Aksiologiya: Jurnal Pengabdian Kepada Masyarakat

Vol.5, No. 1, Februari 2021 Hal 88 - 103

ISSN 2528-4967 (print) dan ISSN 2548-219X (online)

\title{
Perbaikan Lingkungan dengan Penanaman Mangrove Berbasis Masyarakat untuk Mendukung Wisata Pesisir Desa Tapulaga
}

\author{
Aminuddin Mane Kandari', Safril Kasim², La Ode Siwi ${ }^{3}$, \\ Ridwan Adi Surya ${ }^{4}$, La Ode Agus Salim Mando ${ }^{5}$, Asramid Yasin ${ }^{6}$, \\ Herlan Hidayat $^{7}$, dan Terry Y.R. Pristya ${ }^{8}$ \\ 1,2,3,4,6,77 Program Studi Ilmu Lingkungan, FHIL, Universitas Halu Oleo \\ ${ }^{5}$ Program Studi Kehutanan, FHIL, Universitas Halu Oleo \\ ${ }^{8}$ Program Studi Kesehatan Masyarakat, FIKES, UPN Veteran Jakarta \\ Email :manekandaria@yahoo.com², safrilkasim1970@gmail.com², laodesiwi74@ \\ yahoo.com³, adisurya@gmail.com4,14s4n@yahoo.co.id ${ }^{5}$, asramidyasin@uho. \\ ac.id ${ }^{6}$, hidayat.herlan@yahoo.co.id ${ }^{7}$, terry.yuliana@gmail.com ${ }^{8}$
}

\begin{abstract}
ABSTRAK
Perbaikan lingkungan dengan penanaman mangrove berbasis masyarakat untuk mendukung wisata pesisir dilatar belakangi oleh garis pantai mengalami kemunduran dengan tingginya erosi pantai, kurangnya sentuhan iptek dalam pengelolaan mangrove, masyarakat tidak memiliki mata pencaharian alternatif dan kurangnya kesadaran masyarakat untuk menjaga dan memelihara lingkungan. Tujuan program ini adalah terbentuknya unit pemberdayaan masyarakat terhadap ekosistem mangrove, menjadikan ekosistem mangrove sebagai wisata pesisir untuk meningkatkan pendapatan daerah, kesejahteraan masyarakat dan kelestarian alam. Metode yang digunakan meliputi: 1) metode perencanaan: survei lokasi, perijinan, wawancara, pemberian kuesioner, 2) metode pelaksanaan: penyuluhan, pembentukan unit lembaga, pembibitan, persemaian, penanaman dan kerja bakti bersih pantai dan 3) metode evaluasi: meminimalisir kelemahan dan hambatan selama kegiatan berlangsung. Program dilaksanakan pada Juli 2019 di desa Tapulaga kecamatan Soropia kabupaten Konawe. Hasil program yang dicapai: persepsi masyarakat banyak yang setuju desa Tapulaga menjadi daerah ekowisata mangrove, terbentuknya Sahabat Mangrove Desa Tapulaga sebagai lembaga pengelola mangrove dan lembaga pendukung lainya seperti kelompok Pengawas Pesisir Wahana Lestari dan kelompok Nelayan Lestari, bertambahnya 1 unit bedeng persemaian mangrove yang baru yang dapat dijadikan lahan bisnis untuk dijual, penambahan jumlah area kawasan hutan mangrove desa Tapulaga dengan melalui 1000 bibit pohon mangrove yang ditanam dan berkurangnya sampah plastik melalui kerja bakti bersih pantai desa Tapulaga.
\end{abstract}

Kata Kunci: Desa Tapulaga; mangrove; pesisir; wisata

\section{Environmental Improvement with Community-Based Mangrove Planting to Support Coastal Tourism in Tapulaga Village}

\begin{abstract}
Improvement of the environment by planting community-based mangroves to support coastal tourism due to the shoreline has deteriorated with high coastal erosion, lack of science and technology touches in mangrove management, the community lacks alternative livelihoods and lack of community awareness to protect and preserve the environment. The purpose of this program is the formation of a community empowerment unit for mangrove ecosystems, making mangrove ecosystems as coastal tourism to increase regional income, community welfare and nature conservation. The
\end{abstract}


methods used include: 1) planning methods: location surveys, permits, interviews, questionnaires, 2) implementation methods: counseling, the establishment of institutional units, nurseries, nurseries, planting and beach clean service work and 3) evaluation methods: minimizing weaknesses and obstacles during the activity. The program was carried out in July 2019 in Tapulaga village, Soropia sub-district, Konawe regency. Program results achieved: many community perceptions agree that Tapulaga village becomes a mangrove ecotourism area, the formation of Friends of Mangrove Tapulaga Village as a mangrove management institution and other supporting institutions such as the Wahana Lestari Coastal Supervisor group and the Sustainable Fishermen group, an increase in 1 new mangrove nursery unit can be used as a business land for sale, increasing the number of mangrove forest areas in Tapulaga village by going through 1000 mangrove tree seedlings planted and reducing plastic waste through the clean beach service work of Tapulaga village.

Keywords: coastal; mangrove; Tapulaga Village; tourism

\section{PENDAHULUAN}

Indonesia merupakan negara kepulauan yang memiliki garis pantai terpanjang nomor 2 di dunia dengan panjang $99.093 \mathrm{~km}$ (Kementerian Kelautan dan Perikanan RI, 2018). Salah satu daerah yang memiliki garis pantai adalah kabupaten Konawe kecamatan Soropia desa Tapulaga. Wilayah pesisir adalah wilayah pertemuan antara daratan dan laut, ke arah darat meliputi bagian daratan yang masih dipengaruhi oleh sifatsifat laut seperti pasang surut, angin laut dan intrusi garam, sedangkan ke arah laut mencakup bagian laut yang masih dipengaruhi oleh proses alami yang ada di darat seperti sedimentasi dan aliran air tawar serta daerah yang dipengaruhi oleh kegiatan-kegiatan manusia di daratan (Nontji, 2002). Keadaan ini menyebabkan wilayah pesisir menjadi salah satu andalan sumber pendapatan desa Tapulaga.

Wilayah pesisir pada dasarnya tersusun dari berbagai macam ekosistem yang satu sama lain saling berkaitandantidakberdirisendiri,salah satunya adalah ekosistem mangrove. Mangrove adalah tumbuhan khas yang tumbuh di daerah pantai atau pesisir yang dipengaruhi oleh pasang surut.
Hal yang paling mendasar dan penting untuk dipahami adalah bahwa jenis tumbuhan mangrove mampu tumbuh dan berkembang pada lingkungan pesisir yang berkadar garam sangat ekstrim, jenuh air, kondisi tanah yang kurang stabil dan anaerob (Pramudji, 2001). Perubahan atau kerusakan yang menimpa satu ekosistem mangrove akan menimpa ekosistem lainnya. Selain itu wilayah pesisir juga dipengaruhi oleh berbagai macam kegiatan manusia maupun prosesproses alamiah yang terdapat di lahan atas (upland areas) maupun laut lepas (oceans). Kondisi empiris semacam ini mensyaratkan dalam melakukan pengelolaan pesisir dan lautan harus memperhatikan segenap keterkaitan ekosistem yang dapat mempengaruhi perubahan suatu wilayah pesisir.

Guna meminimalisir dampak yang lebih besar lagi terhadap tekanan sumberdaya mangrove, maka diperlukan pemberdayaan masyarakat pesisir yang dilakukan secara intensif sehinggadapatmenjadikanmasyarakat sebagai komponen utama penggerak partisipasif dalam pengembangan tanaman mangrove. Begitu pula sebaliknya rendahnya pemahaman masyarakat terhadap fungsi dan 
peranan tanaman mangrove dapat menyebabkan makin menurunnya daya dukung lingkungan sumberdaya pesisir dan kualitas hidup komunitas penduduk setempat.

Pengembangan tanaman mangrove merupakan usaha yang sangat kompleks untuk dilaksanakan, karena kegiatan tersebut sangat membutuhkan sifat akomodatif masyarakat sekitar kawasan pesisir. Namun demikian sifat akomodatif ini akan lebih dirasakan manfaatnya bilamana keberpihakan terhadap masyarakat pesisir yang sangat rentan terhadap sumberdaya mangrove diberikan porsi yang lebih besar. Pemberian porsi yang besar kepada masyarakat pesisir harus diiringi dengan upaya membangun kesadaran dan persepsi pentingnya arti dan peran hutan mengrove itu sendiri. Pandangan masyarakat pesisir selama ini hanya melihat kepentingan tanaman mangrove dari sudut ekonomi, secara berangsur-angsur digiring kearah kepentingan wisata pesisir.

Kurangnya proses yang akomodatif dalam pemberdayaan masyarakat pesisir terhadap tanaman mangrove dapat menyebabkan tingkat partisipasi masyarakat pesisir yang rendah dalam melakukan pelestarian danrentanterhadapkerusakan tanaman mangrove. Akibat dari kurangnya pemahaman ini masyarakat pesisir lebih banyak mengusahakan tanaman mangrove untuk kegiatan usaha yang mempunyai dampak secara langsung dalam memenuhi kebutuhan hidup seperti pertambakan, pertanian dan kurang memperhatikan pengelolaan tanaman mangrove berbasis wisata pesisir. Oleh karena itu dibutuhkan pemberdayaan serta pengarahan kepada masyarakat melalui program Pengabdian Masyarakat KKN Tematik ini agar dapat meningkatkan kelestarian lingkungan serta perekonomian masyarakat di wilayah pesisir desa Tapulaga.

Desa Tapulaga adalah sebuah desa pesisir tepatnya berada di kecamatan Soropia, kabupaten Konawe, Sulawesi Tenggara yang memiliki luas wilayah 549 ha. Mata pencaharian masyarakat desa Tapulaga digolongkan ke dalam sektor perikanan dan pertanian. Berdasarkan kondisi wilayahnya, sebagian masyarakat desa Tapulaga memiliki mata pencaharian sebagai nelayan. Penghasilan masyarakat desa Tapulaga kecamatan Soropia masih berada pada kisaran menengah kebawah.

Ketergantungan masyarakat terhadap hasil laut masih cukup tinggi, namun ada beberapa kendala yang menghambat mata pencaharian masyarakat desa yang mayoritas adalah nelayan. Kendala yang utama adalah musim, karena pada saat musim penghujan masyarakat yang mayoritas sebagai nelayan tersebut tidak dapat melaut dan pendapatan menurun drastis. Kondisi wilayah pesisir pantai di desa Tapulaga masih belum dikelola dengan baik oleh masyarakat sekitar. Wilayah dari desa Tapulaga masih sedikit ditumbuhi mangrove akibat tereksploitasi. Sehingga timbulah inisiatif dari kami untuk melakukan sosialisasi kepada masyarakat desa Tapulaga untuk 
dapat meningkatkan taraf hidup secara sosial. Program yang kami lakukan yaitu Program Kemitraan Masyarakat dimana program ini merupakan sebuah program pemberian penyuluhan secara langsung terhadap masyarakat desa pesisir dengan pengenalan, penanaman dan pemanfaatan mangrove.

Sehingga pada saat terjadi musim hujan masyarakat yang biasanya tidak dapat melaut beralih profesi dengan memanfaatkan hasil dari mangrove yang telah ditanam. Program yang dilakukan dapat memaksimalkan potensi wilayah yang dapat menjadikan kawasan tersebut sebagai wisata pesisir yang dikelola oleh masyarakat Tapulaga. Mangrove yang kurang terawat dapat dikelola dengan baik agar memberikan manfaat yang maksimal. Dengan pengelolaan dan pelatihan mangrove diharapkan meningkatkan kesadaran masyarakat untuk menjaga komunitas mangrove karena sangat bermanfaat baik bagi ekosistem tersebut maupun kelangsungan hidup masyarakat di dekat kawasan mangrove.

Adanya potensi sekaligus permasalahan di desa Tapulaga, sehingga partisipasi perguruan tinggi (dosen dan mahasiswa) untuk turun secara langsung melaksanakan serangkaian pembelajaran sekaligus pemberdayaan kepada masyarakat. ProgramPengabdianMasyarakatKKN Tematik setidaknya dapat memberikan masukan dan pembelajaran kepada masyarakat khususnya masyarakat pesisir melalui perbaikan lingkungan dengan penanaman mangrove berbasis masyarakat untuk mendukung program wisata pesisir di desa Tapulaga kecamatan Soropia kabupaten Konawe.

Tujuan dari program ini adalah terbentuknya unit pemberdayaan masyarakat terhadap ekosistem mangrove, menjadikan ekosistem mangrove sebagai wisata pesisir untuk meningkatkan pendapatan daerah serta kelestarian alam, meningkatkan kesejahteraan masyarakat desa Tapulaga.

\section{METODE PENELITIAN}

Kegiatan ini dilaksanakan di desa Tapulaga, kecamatan Soropia, kabupaten Konawe, Provinsi Sulawesi Tenggara merupakan kegiatan yang terintegrasi dengan menggunakan beberapa tahapan, yaitu:

1. Metode "Perencanaan" yaitu langkah pertama sebelum pelaksanaan program yang terdiri dari:

a. Survei lokasi yaitu melihat bagaimana kondisi sasaran dan menggali masalah yang ada di desa Tapulaga.

b. Perizinan kepada pemerintah desa, karang taruna, dan PKK untuk penerapan program kemitraan masyarakat.

c. Wawancara dan pengisian kuesioner dengan warga untuk mengetahui seberapa jauh pengetahuan mereka mengenai mangrove.

2. Metode

"Pelaksanaan" merupakan tahapan utama dari program Pengabdian Masyarakat KKN Tematik yang terbagi menjadi: 
a. Sosialisasi

program

Pengabdian Masyarakat KKN

Tematik, yaitu pendekatan dan penyuluhan mengenai program yang akan dilakukan kepada masyarakat baik dari pihak penerintah desa, karang taruna, dan ibu-ibu PKK. Sosialisasi memberitahu pentingnya keberadaan mangrove khususnya sebagai peredam gelombang tsunami serta pemanfaatannya yang sangat menguntungkan.

b. Penanaman mangrove di sekitar pantai yang bertujuan memberi edukasi kepada masyarakat serta merehabilitasi ekosistem mangrove yang telah rusak. Program ini memberikan 1000 bibit mangrove gratis kepada masyarakat untuk ditanam. Sebelum penanaman dimulai masyarakat terlebih dulu diberi tahu teknis dari menanam mangrove dengan benar. Pemerintah desa, karang taruna, dan ibu-ibu PKK ikut turun langsung dalam kegiatan ini. Setelah penanaman dilakukan selanjutnya adalah praktik mengenai cara merawat dan menjaga mangrove agar bernilai ekonomi.

c. Kerja bakti bersih pantai yang bertujuan menyadarkan masyarakat pentingnya kebersihan lingkungan sekitar pantai.

3. Metode "Evaluasi", adalah tahap terakhir dimana dalam setiap melakukan kegiatan tersebut harus melakukan evaluasi dengan mempertimbangkan hasil dari proses perencanaan dan pelaksanaan. Evaluasi yang dilakukan bertujuan untuk menilai dan memperbaiki kekurangan serta kelemahan dalam melakukan proses perencanaan dan pelaksanaan. Evaluasi dianggap penting karena jika pelaksanaan dan perencanaan tersebut berlangsung dalam jangka waktu yang lama maka kekurangan dan kelemahan tersebut dapat diminimalisir. Evaluasi dan keberlanjutan program kami sajikan dalam Tabel 1 berikut.

Tabel 1: Analisis Indikator Keberhasilan Program Pendampingan Masyarakat Desa Tapulaga

\begin{tabular}{lllc}
\hline No & \multicolumn{1}{c}{ Nama Pekerjaan } & \multicolumn{1}{c}{ Program } & \multicolumn{1}{c}{ Target Program } \\
\hline \multirow{2}{*}{1} & $\begin{array}{l}\text { Sosialisasi Ekowisata } \\
\text { Mangrove }\end{array}$ & $\begin{array}{l}\text { Penyuluhan } \\
\text { P e n g i s i a n } \\
\text { kuesioner }\end{array}$ & $\begin{array}{c}\text { Persepsi masyarakat akan } \\
\text { setuju desa Tapulaga dijadikan } \\
\text { sebagai ekowisata mangrove }\end{array}$ \\
\hline \multirow{2}{*}{$\begin{array}{l}\text { Membentuk Unit } \\
\text { Lembaga Pengelola } \\
\text { Mangrove }\end{array}$} & $\begin{array}{l}\text { Rapat koordinasi } \\
\text { bersama aparat } \\
\text { desa dan } \\
\text { masyarakat }\end{array}$ & Terbentuknya lembaga \\
\hline
\end{tabular}




\begin{tabular}{|c|c|c|c|}
\hline 3 & Pembibitan Mangrove & $\begin{array}{l}\text { P e n y u } 1 \text { u h a n } \\
\text { teknis } \\
\text { Menyiapkan alat } \\
\text { dan bahan } \\
\text { Mengumpulkan } \\
\text { bibit mangrove } \\
\mathrm{u} n \mathrm{n} \mathrm{u} \mathrm{k} \\
\text { disemaikan }\end{array}$ & Terdapat bedeng persemaian \\
\hline 4 & Penanaman Mangrove & $\begin{array}{l}\text { P e n y u } 1 \text { u h a } \mathrm{n} \\
\text { teknis } \\
\text { Menyiapkan alat } \\
\text { dan bahan } \\
\text { Menanam bibit } \\
\text { mangrove yang } \\
\text { telah disemaikan }\end{array}$ & $\begin{array}{c}\text { Bertambah luasan areal hutan } \\
\text { mangrove }\end{array}$ \\
\hline 5 & Kerja Bakti Bersih Pantai & $\begin{array}{l}\text { P e n y u } 1 \text { u h a n } \\
\text { teknis } \\
\text { Menyiapkan alat } \\
\text { dan bahan } \\
\text { Membersihkan } \\
\text { pantai bersama- } \\
\text { sama dengan } \\
\text { masyarakat }\end{array}$ & $\begin{array}{l}\text { Volume sampah plastik di } \\
\text { pantai akan berkurang }\end{array}$ \\
\hline
\end{tabular}

HASIL DAN PEMBAHASAN Sosialisasi Ekowisata Mangrove

Pengabdian Masyarakat KKN Tematik yang dilaksanakan di desa Tapulaga, kecamatan Soropia, kabupaten Konawe, Sulawesi Tenggara. Desa Tapulaga merupakan desa pesisir pantai dengan luas wilayah $5,49 \mathrm{~km}^{2}$ yang terdiri atas 3 dusun. Desa Tapulaga memiliki jumlah penduduk 348 jiwa dengan 85 jumlah kepala keluarga (KK), terdiri dari 175 laki-laki dan 173 perempuan (BPS, kecamatan Soropia dalam angka, 2018).

Berdasarkan lokasi desa Tapulaga yang strategis dimana terletak di daerah pesisir dan merupakan jalur penting kawasan wisata sehingga desa Tapulaga penting untuk didukung menjadi desa ekowisata pesisir dengan cara perbaikan lingkungan dengan penanaman mangrove berbasis masyarakat. Melihat keadaan kawasan hutan mangrove desa Tapulaga mengalami kerusakan yang cukup tinggi sehingga perlu dilakukan sosialisasi ekowisata mangrove desa Tapulaga dengan mendorong masyarakat untuk aktif melakukan reboisasi hutan mangrove tersebut.

Peran aktif dalam mengelola potensi ekowisata ini penting karena pengetahuan alam dan potensi budaya memiliki nilai jual sebagai daya tarik ekowisata. Perkembangan ekowisata mempengaruhi masyarakat pada aspek ekologi, sosial, dan ekonomi. Salah satu tujuan dari kegiatan dari Pengabdian MasyarakatKKN Tematik ini adalah untuk meningkatkan kesadaran dan partisipasi masyarakat 
dalam mendukung program ekowisata di desa Tapulga kecamatan Soropia kabupaten Konawe.

Hasil sosialisasi ekowisata mangrove di desa Tapulaga terkait program perbaikan lingkungan desa Tapulaga untuk dijadikan destinasi ekowisata mangrove maka dengan itu kami melakukan observasi awal khususnya pada minggu pertama yaitu sosialisasi penyuluhan penanaman mangrove dangan diskusi kelompok dan membagikan quesioner terhadap masyarakat di desa Tapulaga untuk mengetahui respon dari masyarakat desa Tapulaga (Gambar 1). Berbagai tanggapan positif dari masyarakat untuk program ini, dari hasil observasi awal yang kami lakukan bahwa masyrakat merespon baik terhadap program ekowisata yang berbasis masyarakat karena mengingat desa
Tapulaga sangat cocok untuk dijadikan sebagai destinasi wisata pesisir.

Hal ini didukung oleh pendapat Amin, et al., (2016) bahwa masalah pengelolaan yang memperhatikan aspek konservasi lingkungan sumberdaya laut dan pesisir lebih dikedepankan dan disosialisasikan secara luas kepada penentu kebijakan dan masyarakat pesisir sehingga mereka memiliki persepsi yang sama dalam melihat permasalahan yang ada di daerah pesisir.

Lebih lanjut Hardianti, $d k k$, (2014) menambahkan bahwa pengetahuan konservasi dengan persepsi masyarakat tentang kegiatan penanaman mangrove menunjukkan kekuatan hubungan karena persepsi dapat dibentuk dari berbagai faktor, bukan hanya pengetahuan. Faktorfaktor tersebut meliputi faktor
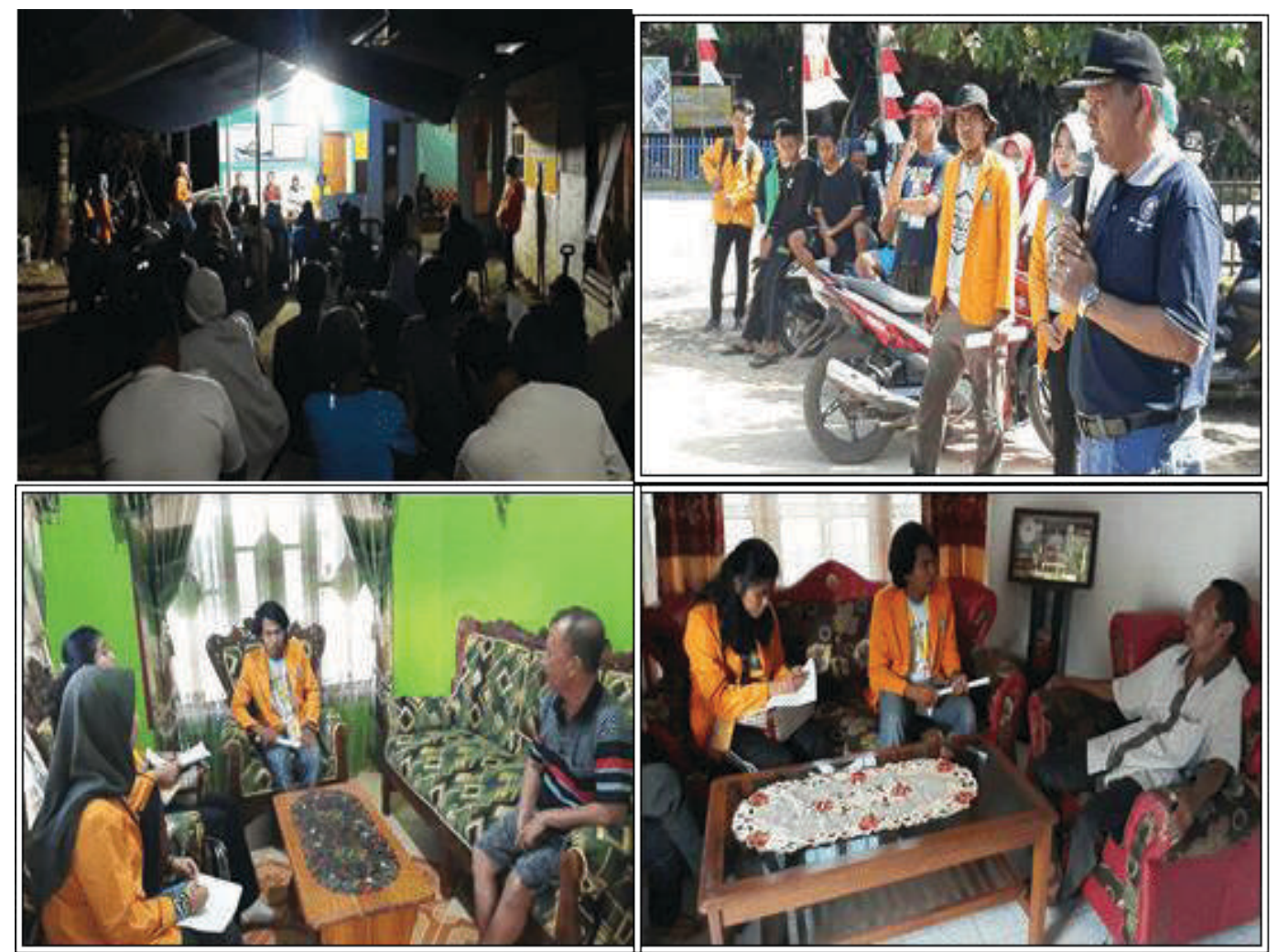

Gambar 1: Sosialisasi Ekowisata Mangrove 
internal dan eksternal. Faktor internal diantaranya kebutuhan psikologis, latar belakang, kepribadian, sikap dan kepercayaan diri, serta penerimaan diri. Sedangkan faktor eksternal diantaranya intensitas, ukuran, kontras, gerakan, ulangan, dan keakraban serta sesuatu yang baru. Faktor-faktor tersebut juga dapat membentuk persepsi nelayan tentang kegiatan penanaman mangrove.

\section{Membentuk Unit Lembaga Pengelola Mangrove}

Lembaga atau kelompok masyarakat peduli lingkungan pesisir khususnya ekosistem mangrove telah didirikan pada tanggal 21 Agustus 2019 di desa Tapulaga kecamatan Soropia kabupaten Konawe. Kelompok masyarakat ini diberi nama Sahabat Mangrove Desa Tapulaga. Kelompok masyarakat ini didirikan dengan tujuan menghimpun masyarakat usia remaja hingga dewasa di desa Tapulaga untuk peduli terhadap kelestarian lingkungan ekositem mangrove di desa Tapulaga. Adapun luaran yang diharapkan kedepannya ialah terciptanya kelestarian lingkungan ekosistem mangrove desa Tapulaga, terciptanya lapangan pekerjaan bagi masyarakat desa Tapulaga, menumbuhkan kreatifitas dan inovasi terbarukan terhadap pemanfaatan mangrove desa Tapulaga.

Sahabat Mangrove merupakan suatu wadah yang diharapkan mampu untuk membimbing generasi penerus desa Tapulaga agar tetap konsisten dan berkelanjutan dalam melestarikan ekosistem mangrove untuk mendukung program ekowisata pesisir desa Tapulaga.

Sahabat Mangrove Desa Tapulaga saat ini terdiri atas 8 orang anggota tetap dengan struktur organisasi ketua, sekertaris, bendahara dan 5 orang lainnya merupakan anggota. Adapun struktur organisasi kelompok masyarakat sahabat Mangrove Desa Tapulaga adalah sebagai berikut:

$\begin{array}{ll}\text { Ketua } & \text { : Muhammad Asdar } \\ \text { Sekertaris } & \text { : Muhammad Syahril } \\ \text { Bendahara } & \text { : Muhammad Akbar } \\ \text { Anggota } & : \text { - Muhammad Ajran } \\ & \text { - Awal Pratama } \\ & \text { - Muhammad Indra } \\ & \text { - Rusman } \\ & \text { - Muhammad } \\ & \text { Ardiansyah }\end{array}$

Berdasarkan hasil survei di lapangan desa Tapulaga saat ini terdiri atas 89 kepala keluarga dengan mayoritas warganya lanjut usia. Diduga tingkat kepekaan remaja terhadap lingkungan pesisir mangrove relatif rendah sehingga dinilai perlu didirikannya kelompok masyarakat Sahabat Mangrove Desa Tapulaga. Kondisi lingkungan desa Tapulaga dinilai cukup baik untuk tumbuh kembang bibit bakau. Hal ini didukung pula dengan keberhasilan salah satu warga dusun satu desa Tapulaga atas nama Bakrieng yang telah berhasil mengirimkan lebih dari 1000 bibit mangrove yang dibibitkannya sendiri di desa Tapulaga bahkan bibit tersebut dipesan langsung oleh salah satu perusahaan tambang ternama bahkan hingga keluar dari Provinsi Sulawesi Tenggara.

Unit-unit lembaga lainnya yang 


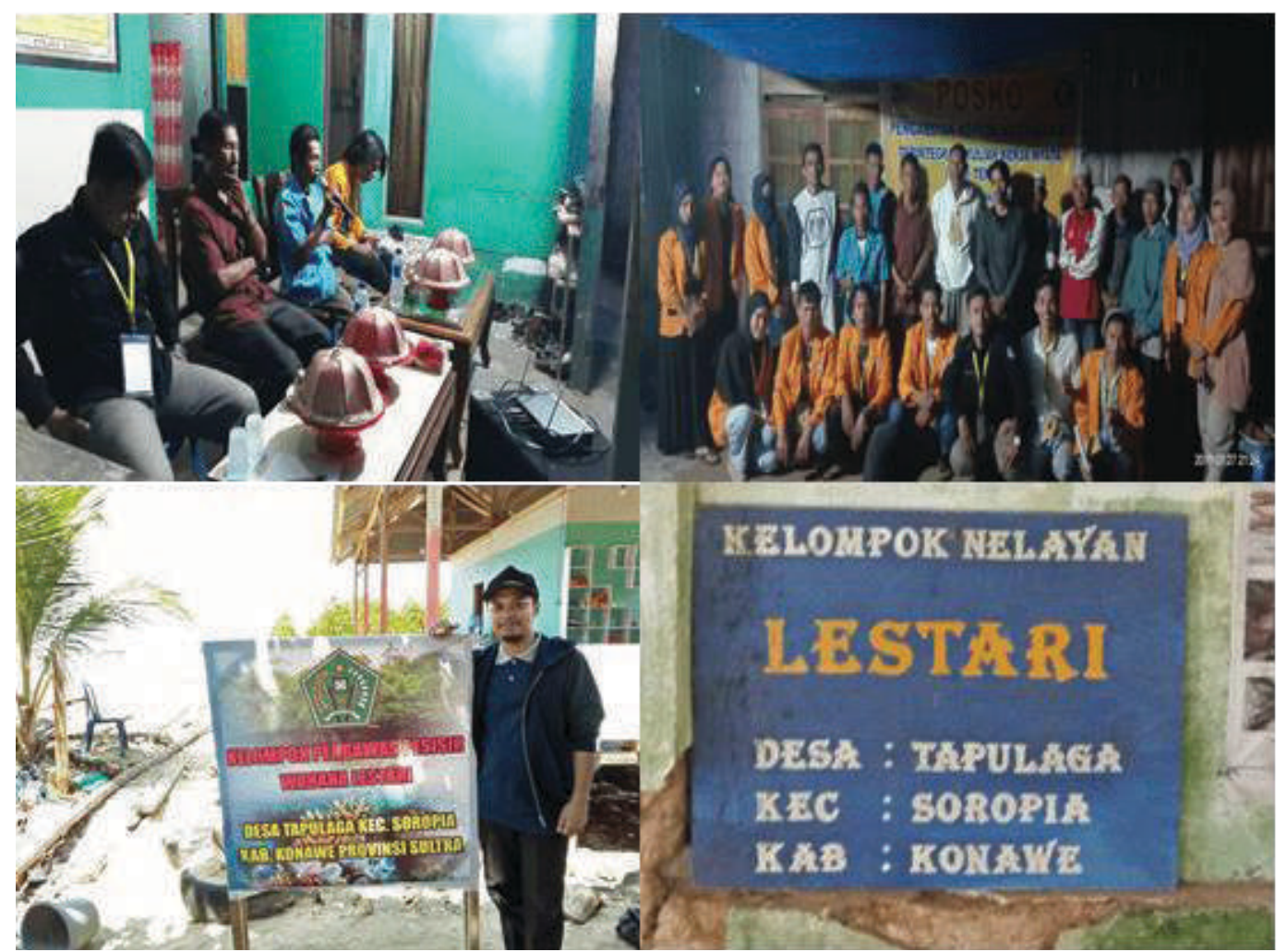

Gambar 2: Unit Lembaga Terkait di Desa Tapulaga

sudah ada di desa Tapulaga dapat menjadi pendukung dalam program ekowisata mangrove seperti kelompok Pengawas Pesisir Wahana Lestari dan kelompok Nelayan Lestari dapat berkolaborasi dan saling memperkuat sehingga dapat mendorong dan mewujudkan desa Tapulaga menjadi desa Ekowisata Mangrove berbasis masyarakat (Gambar 2).

Banyaknya penggunaan hutan dan beragamnya alih fungsi hutan telah menyebabkan penurunan terhadap sumberdaya hutan di Indonesia. Kondisi menurunnya potensi sumberdaya hutan di Indonesia membutuhkan suatupengelolaanhutan yang berkelanjutan. Salah satu prinsip kelestarian hutan adalah perlunya peran para pihak agar terciptanya suatu pola hubungan kelembagaan. Salah satu pihak yang terlibat dalam pengelolaan hutan adalah Lembaga Swadaya Masyarakat (Utami dan Maryudi, 2016).

\section{Pembibitan Mangrove}

Kondisi substratalamipesisir desa Tapulaga berupa pasir, bebatuan dan lumpur dinilai cocok untuk berbagai jenis tanaman mangrove terkhusus mangrove dengan jenis Rhizopora sp. atau dengan nama lokal biasa disebut bakau Beropa. Kondisi geografis desa Tapulaga yang terletak dipinggirpantai dan wilayahnya yang didominasi oleh pesisir dan lautan dangkal serta perolehan sumber air tawar yang cukup dapat dijadikan tolak ukur keberhasilan desa Tapulaga sebagai desa pembibitan mangrove. Dengan adanya lokasi pembibitan mangrove desa Tapulaga yang didampingi oleh kelompok masyarakat Sahabat 

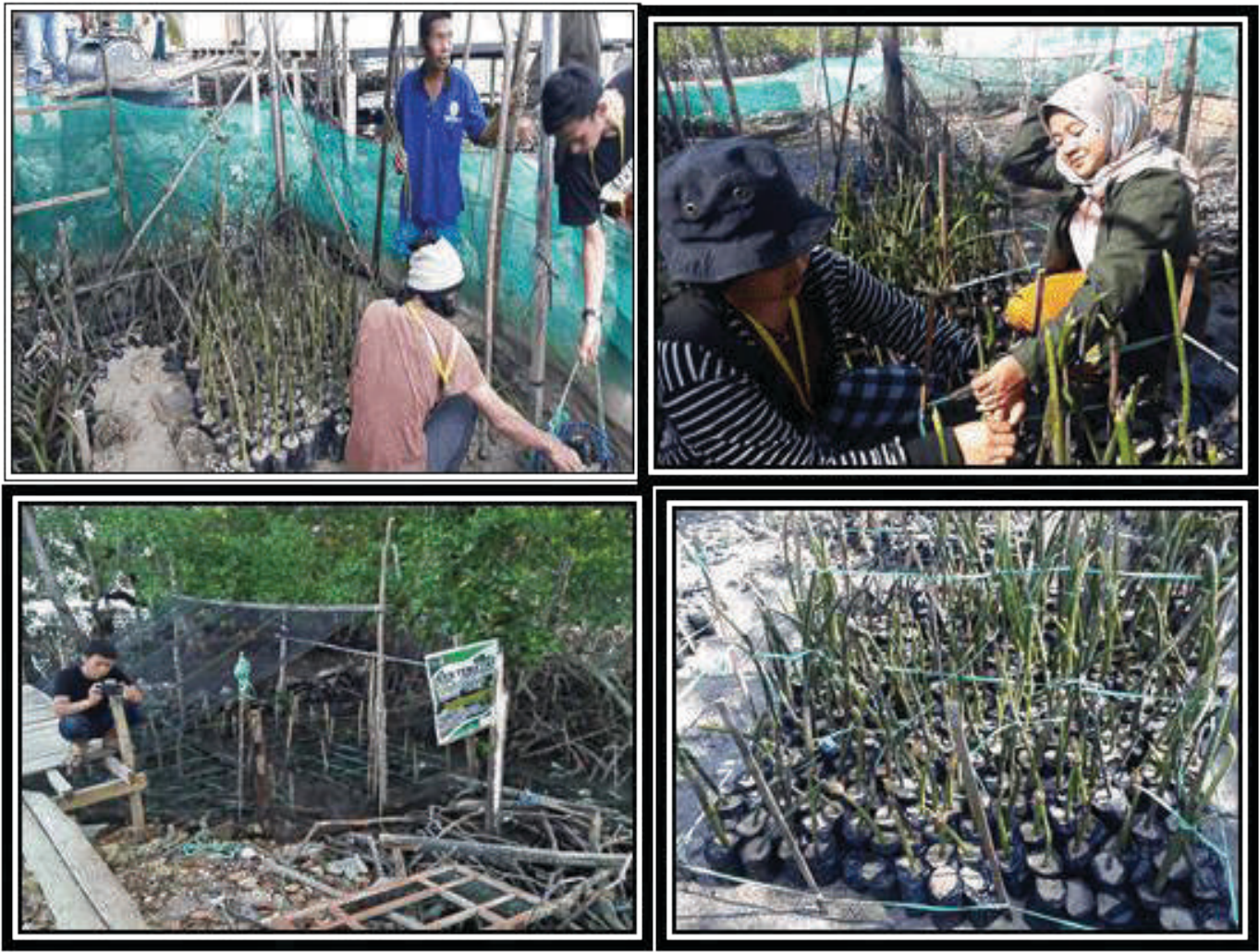

Gambar 3: Pembibitan Mangrove di Desa Tapulaga

Mangrove diharapkan mampu untuk meningkatkan kesejahteraan warga dan ekosistem mangrove pesisir desa Tapulaga.

Bibit yang kami dapatkan diperoleh dari pohon induk yang cukup umur dan sehat dengan jenis tanaman mangrove yaitu Rhizopora yang berbuah sepanjang musim bibit. Teknik pengambilan benih yaitu dengan mengambil bibit yang sudah tua dengan ciri-ciri buahnya pada bagian bawah memiliki bintik-bintik hitam. Setelah benih yang dipanen kemudian kami memasukkan ke dalam karung dengan merendam di air laut selama 3 hari, setelah itu kami mengadakan proses pemilahan bibit guna untuk mengetahui bibit mana yang unggul dan siap untuk ditanam ke dalam media tanam. Jadi bibit yang siap ditanam yaitu sebanyak 160 buah.
Sebelum ditanam terlebih dahulu kami menyiapkan media tanam, kami memasukkan tanah ke dalam polibag sebanyak dengan jumlah benih yang kami peroleh. Media tanam yang kami gunakan berasal dari sekitaran pohon induk.

Lokasi bedeng, dipilih yang berdekatan dengan lokasi penanaman mangrove. Hal ini, bertujuan untuk mempermudah distribusi bibit mangrove pada saat penanaman (Priyono, 2010).

Penanaman benih pertama yang kami lakukan pada pagi hari di depan laboratorium lapangan tepatnya di dusun I hari Minggu, 4 Agustus 2019 dibantu dengan siswa-siswi SD Negeri 2 Tapulaga dan SMP Negeri 3 Soropia yang sebelum sudah diberikan penyuluhan tentang pembibitan yang 
baik sebelumnya. Teknik penanaman bibit dengan memasukkan bagian ujung radikula bibit ke dalam polibag dengan mengusahakan bibit berdiri dengan baik. Penanaman bibit kedua kami lakukan sekaligus pembersihan persemaian sebanyak 340 buah. Penanaman bibit ketiga kami lakukan di dusun III, Rabu, 21 Agustus 2019 tepatnya pada persemaian di belakang rumah kepala desa Tapulaga. Bibit yang kami tanam sebanyak 47 buah kami menanam bibit dengan menggunakan teknik yang sama (Gambar 3).

\section{Penanaman Mangrove}

Penanaman yang kami lakukan di desa Tapulaga kecamatan Soropia kabupaten Konawe pada hari Minggu tanggal 04 Agustus 2019, kegiatan penanaman ini, didampingi langsung oleh Ketua Tim Pengabdian Masyarakat KKN Tematik serta Dosen Pembimbing Lapangan, Kepala Desa Tapulaga, Sekcam, Ketua Karangtaruna, Kepala Dusun, Ketua RT, dan Masyarakat Desa Tapulaga. Kegiatan penanaman ini dihadiri juga oleh beberapa media baik media online maupun media cetak. Sebelum dilakukan penanaman terlebih dahulu kita menyiapkan lokasi penanaman, lokasi penanaman mangrove terletak di Dusun 1 sekitaran Laboratorium Lapangan Fakultas Kehutanan dan Ilmu Lingkungan. Adapun alat dan bahan yang kami gunakan yaitu: ajir untuk penahan bibit mangrove yang telah ditanam, jaring digunakan untuk pembuatan plot sekaligus penahan ombak dan sampah, pacul untuk menggali lubang dan tali rafia untuk mengikat bibit yang ditanam ke ajir. Mangrove yang ditanam di desa Tapulaga berjumlah 600 pohon yang ditanam secara bersamaan oleh seluruh masyarakat yang hadir. Luas wilayah lokasi tanam 50 Meter x 50 Meter, dengan jarak tanam 2 Meter. Bibit yang ditanam adalah bibit dari persemaian kepala Karangtaruna desa Tapulaga yaitu pak Bakring.

Penanaman kami lakukan tidak hanya 1 kali penanaman, namun setiap minggu setelah penanaman masal. Penanaman kedua kami lakukan hanya seluruh peserta Pengabdian Masyarakat KKN Tematik untuk mengganti bibit yang mati setelah ditanam kemudian menambah jumlah bibit yang ditanaman. Jumlah bibit yang kami tanam sampai berjumlah 1000 pohon karena kami menyesuaikan dengan bibit yang siap tanam dan kondisi pasang surutnya air. Penanaman terakhir kami lakukan bersama dengan santri dari Rumah Qur'an Desa Tapulaga. Santri yang melakukan penanaman bersama mahasiswa Pengabdian Masyarakat KKN Tematik kurang lebih 20 santri. Penanaman ini sama dengan penanamankeduayaitumenggantibibit yang mati dan menambah jumlah bibit yang ditanam. Penanaman mangrove yang kami lakukan disambut hangat oleh seluruh masyarakat sekitar, masyarakat sangat antusias dengan adanya penanaman magrove karena dengan adanya penanaman mangrove dapat memperbaiki kembali kondisi lingkungan dan dapat menjadikan desa Tapulaga sebagai desa ekowisata 
mangrove (Gambar 4).

Menurut Adam dan Putri (2018) menjelaskan bahwa beberapa kerusakan-kerusakan pada beberapa sisi pantai. Kerusakan itu bukan hanya karena faktor alam (akibat abrasi dan pengikisan bibir pantai oleh ombak) tetapi juga karena terjadi penebangan hutan oleh warga untuk sekedar tempat kapal-kapal bersandar, dan juga kerusakan yang dibuat oleh pabrikpabrik yang ada disekitar lokasi pantai untuk membuang limbah pabrik. Untuk itu sebelum semuanya berjalan terlalu jauh yang berdampak pada kerusakan pantai yang semakin hari semakin tidak terkendali, maka kami mencoba melakukan penyuluhan dan pelatihan sekaligus penanaman pohon mangrove. yang berjumlah 14 orang. Hasil dari pembersihan pantai, khususnya di dusun III desa Tapulaga adalah jumlah sampah anorganik lebih dominan, dengan jenis sampahnya berupa botol minuman, bungkusan deterjen bubuk dan hasil bungkusan berbagai jenis Snack. Maka, jenis sampah yang tersebar di desa Tapulaga merupakan sampah plastik sekali pakai. Sampah plastik merupakan salah satu sampah yang sulit terurai dan apabila sampah plastik mencemari laut akan mengancam kehidupan organisme yang hidup dalam laut dan banyak kasus yang ditemukan seperti ikan, paus, penyu dan lainnya di dalam perutnya terdapat serpihan plastik. Oleh karena itu sangat penting menyadarkan masyarakat untuk tidak

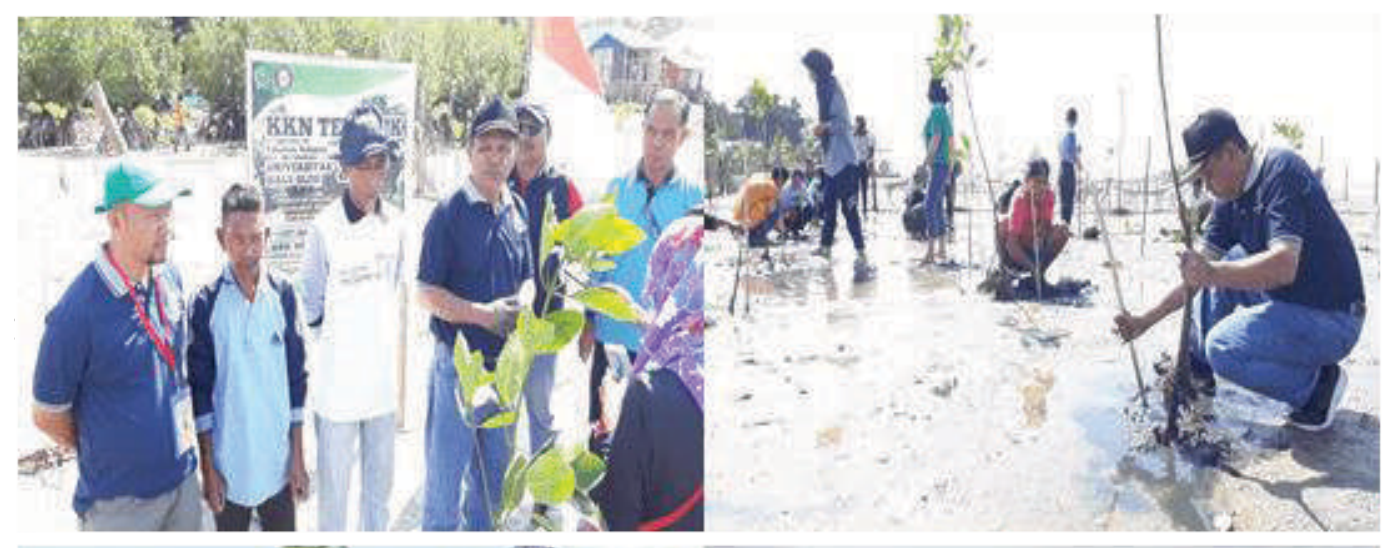

Gambar 4: Penanaman Mangrove di Pantai Desa Tapulaga

\section{Kerja Bakti Bersih Pantai}

Bersih-bersih pantai merupakan program kerja terakhir yang dilakukan pada tanggal 18 Agustus 2019. Kegiatan ini dilakukan dengan tujuan untuk memberikan kesadaran akan pentingnya kebersihan pantai dari berbagai jenis sampah terutama sampah anorganik. Bersih-bersih pantai ini melibatkan anak-anak desa Tapulaga yang berusia 5 tahun ke atas sembarangan membuang sampah di pantai dan di laut (Gambar 5).

Salah satu upaya yang diharapkan dapat mendukung kebersihan pesisir adalah upaya pro-aktif dari elemen masyarakat. Masyarakat dalam hal ini adalah masyarakat lokal serta wisatawan. Handaka, dkk., (2007) menyarankan agar dilakukan upaya kerja bakti secara rutin untuk membersihkan pantai sebagai salah 


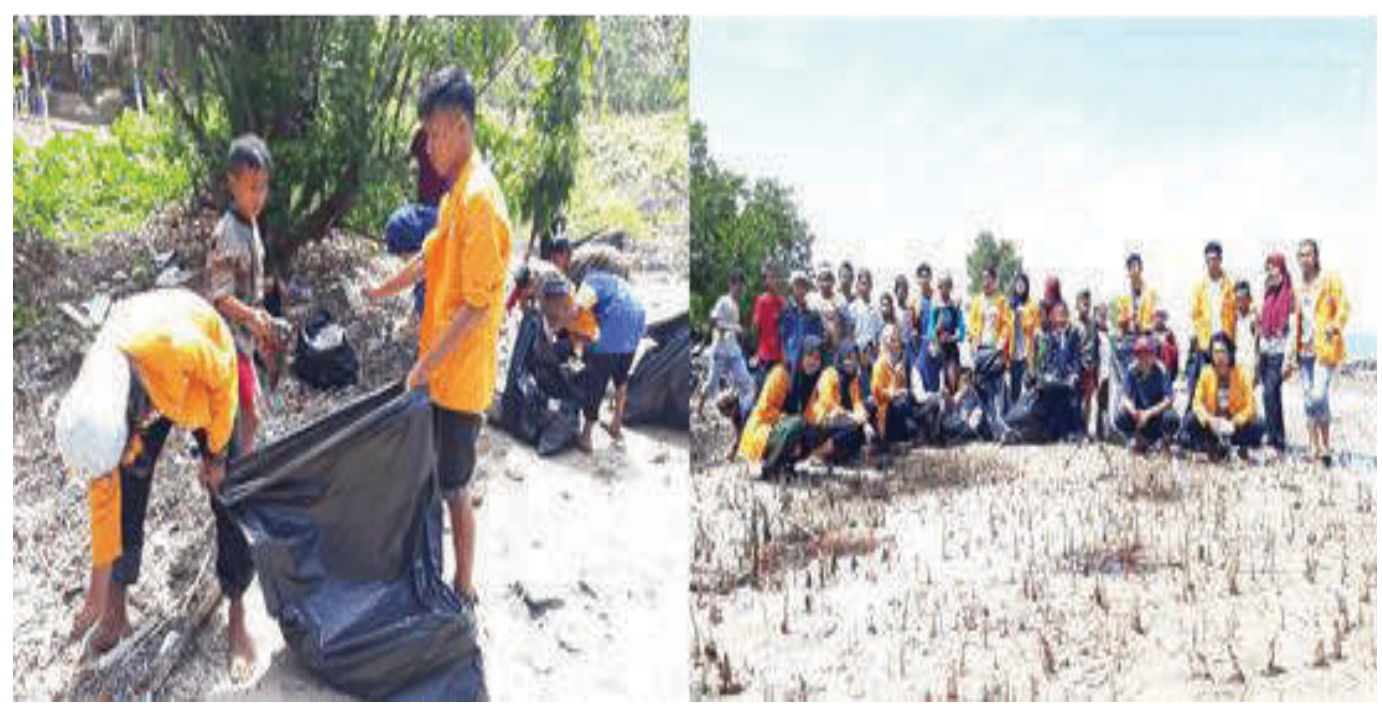

Gambar 5: Kerja Bakti Bersih Pantai di Desa Tapulaga

satu langkah yang dapat diambil untuk menjaga kelestarian lingkungan pesisir. Hal ini selaras dengan berbagai aktifitas atau aksi yang dilakukan oleh masyarakat internasional yaitu Ocean Concervacy secara rutin melakukan kampanye bersih pantai (coastal cleanup). Lembaga ini melakukan standarisasi terhadap pencemar yang ditemukan di pesisir, danau dan laut.

\section{Capaian Program Pengabdian Masyarakat KKN Tematik}

Capaian program Pengabdian Masyarakat KKN Tematik selama 30 hari dapat dilihat dari: 1) Persepsi masyarakat banyak yang setuju desa Tapulaga menjadi daerah ekowisata mangrove hal ini dapat dilihat pada saat diskusi kelompok dan pengisian kuesioner. 2) Terbentuknya Sahabat Mangrove Desa Tapulaga sebagai lembaga pengelola mangrove agar supaya kegiatan persemaian dan pemeliharan serta pengawasan mangrove tetap berkelanjutan. 3) Bertambahnya 1 unit bedeng persemaian mangrove yang baru yang berlokasi di belakang rumah Kepala Desa Tapulaga sehingga dapat menjadi lahan bisnis bagi masyarakat setempat untuk bibitnya dapat dijual. 4) Penambahan jumlah area kawasan hutan mangrove desa Tapulaga dengan melalui 1000 bibit pohon mangrove yang ditanam dan 5) Berkurangnya sampah plastik di pantai melalui kerja bakti bersih pantai di desa Tapulaga dimana agar kondisi tersebut berkelanjutan diperlukan armada pengangkut sampah yang memadai. Untuk lebih jelasnya dapat dilihat pada Tabel 2.

Tabel 2: Capaian Program KKN Tematik di Desa Tapulaga

\begin{tabular}{lllc}
\hline No & \multicolumn{1}{c}{ Nama Pekerjaan } & \multicolumn{1}{c}{ Program } & Hasil Program \\
\cline { 2 - 3 } 1 & $\begin{array}{l}\text { Sosialisasi Ekowisata } \\
\text { Mangrove }\end{array}$ & Pengisian kuesioner & $\begin{array}{c}\text { Persepsi Masyarakat Banyak } \\
\text { yang Setuju desa Tapulaga } \\
\text { menjadi Ekowisata Mangrove }\end{array}$ \\
\hline 2 & $\begin{array}{l}\text { Membentuk Unit Lembaga } \\
\text { Pengelola Mangrove }\end{array}$ & $\begin{array}{l}\text { Rapat koordinasi } \\
\text { bersama aparat desa } \\
\text { dan masyarakat }\end{array}$ & $\begin{array}{c}\text { Terbentuknya Sahabat } \\
\text { Mangrove Desa Tapulaga }\end{array}$ \\
\hline
\end{tabular}




\begin{tabular}{|c|c|c|c|}
\hline \multirow{3}{*}{3} & \multirow{3}{*}{ Pembibitan Mangrove } & Penyuluhan teknis & \multirow{3}{*}{$\begin{array}{l}\text { Bertambahnya Bedeng } \\
\text { Persemaian yang Baru }\end{array}$} \\
\hline & & $\begin{array}{l}\text { Menyiapkan alat dan } \\
\text { bahan }\end{array}$ & \\
\hline & & $\begin{array}{l}\text { Mengumpulkan bibit } \\
\text { mangrove untuk } \\
\text { disemaikan }\end{array}$ & \\
\hline \multirow{3}{*}{4} & \multirow{3}{*}{ Penanaman Mangrove } & Penyuluhan teknis & \multirow{3}{*}{$\begin{array}{c}1000 \text { Bibit Pohon Mangrove } \\
\text { yang Ditanam }\end{array}$} \\
\hline & & $\begin{array}{l}\text { Menyiapkan alat dan } \\
\text { bahan }\end{array}$ & \\
\hline & & $\begin{array}{l}\text { Menanam bibit } \\
\text { mangrove yang telah } \\
\text { disemaikan }\end{array}$ & \\
\hline \multirow{3}{*}{5} & \multirow{3}{*}{ Kerja Bakti Bersih Pantai } & Penyuluhan teknis & \multirow{3}{*}{$\begin{array}{c}\text { Berkurangnya Sampah Plastik } \\
\text { di Pantai }\end{array}$} \\
\hline & & $\begin{array}{l}\text { Menyiapkan alat dan } \\
\text { bahan }\end{array}$ & \\
\hline & & $\begin{array}{l}\text { Membersihkan pantai } \\
\text { bersama-sama dengan } \\
\text { masvarakat }\end{array}$ & \\
\hline
\end{tabular}

\section{Kendala dan Keberlanjutan Program}

Pengabdian masyarakat yang disatukan dengan program Pengabdian Masyarakat KKN Tematik Perguruan Tinggi ini diharapakan dapat berlangsung secara berkelanjutan. Program ini diharapkan tidak sekedar menjadi program atau proyek semata, tetapi betul-betul dapat diimplementasikan oleh masyarakat desa Tapulaga. Pada akhirnya segala penerapan metode yang diberikan kepada masyarakat dapat digunakan untuk menyokong perekonomian dalam rumah tangga mereka dan untuk menjawab persoalan yang selama ini mereka hadapi, sehingga secara ekonomi mereka dapat mandiri.

Agar kegiatan ini dapat berlangsung secara berkelanjutan, maka pelibatan anggota masyarakat sebagai kunci utama dalam meneruskan kegiatan program tetap dilaksanakan. Beberapa strategi agar kegiatan ini dapat berlangsung secara berkelanjutan antara lain: 1) Desa Tapulaga dijadikan sebagai desa binaan oleh Fakultas Kehutanan dan Ilmu Lingkungan Universitas Halu Oleo (FHIL UHO). Manfaat dari desa binaan ini adalah masyarakat tersebut akan diikutsertakan dalam setiap kegiatan yang diakukan di wilayah mereka. Manfaat lainnya adalah dosen FHIL UHO dapat berkomunikasi secara intensif dan menanyakan persoalan dan hasil apa saja yang telah dicapai desa tersebut. 2) Desa binaan yang telah mengalami kesuksesan, dalam artian tujuan program dapat tercapai maka akan dijadikan desa percontohan bagi desa lainnya. 3) Dalam menghadapi kendala persaingan ekonomi bagi masyarakat desa Tapulaga, maka pihak Tim FHIL UHO telah membuat MoA (Memorandum of Agreement) atau Nota Kesepakatan dengan pihak FHIL UHO bertujuan untuk mengoperasikan bersama Laboratorium Lapangan FHIL UHO-Masyarakat Desa 
Tapulaga dengan objek kesepakatan ini berupa lahan pesisir seluas minimal 1 Ha yang diperuntukkan sebagai area rehabilitasi dan perlindungan hutan mangrove selama 5 tahun kedepan. Dengan adanya MoA tersebut terjalin kerjasama sehingga mangrove kembali pulih dan dapat dikembangkan menjadi ekowisata mangrove setempat sehingga dapat meningkatkan tingkat perekonomian masyarakat desa Tapulaga.

\section{SIMPULAN}

Program pengabdian kepada masyarakat terintegrasi kuliah kerja nyata tematik (KKN Tematik) melalui perbaikan lingkungan dengan penanaman mangrove berbasis masyarakat untuk mendukung program wisata pesisir di desa Tapulaga kecamatan Soropia kabupaten Konawe berdampak positif. Kondisi tersebut terlihat dari hasil yang dicapai pada kegiatan ini yaitu: 1) Persepsi masyarakat banyak yang setuju desa Tapulaga menjadi daerah ekowisata mangrove. 2) Terbentuknya Sahabat Mangrove desa Tapulaga sebagai lembaga pengelola mangrove dan lembaga pendukung lainya seperti kelompok Pengawas Pesisir Wahana Lestari dan kelompok Nelayan Lestari. 3) Bertambahnya 1 unit bedeng persemaian mangrove yang baru yang dapat dijadikan lahan bisnis untuk dijual. 4) Penambahan jumlah area kawasan hutan mangrove desa Tapulaga dengan melalui 1000 bibit pohon mangrove yang ditanam dan 5) Berkurangnya sampah plastik di pantai melalui kerja bakti bersih pantai di desa Tapulaga.

\section{UCAPAN TERIMA KASIH}

Terima kasih kami ucapkan kepada LPPM Universitas Halu Oleo atas dukungan dana yang bersumber dari DIPA Universitas Halu Oleo Tahun Anggaran 2019. Terima kasih juga kami ucapkan kepada pemerintah Kabupaten Konawe Kecamatan Soropia Propinsi Sulawesi Tenggara atas kerjasamanya melalui program Pengabdian Kepada Masyarakat Terintegrasi Kuliah Kerja Nyata Tematik(KKN Tematik). Penghargaan kami berikan kepada Kepala Desa dan Masyarakat Desa Tapulaga atas kesediaannya menjadi mitra sehingga program ini berjalan dengan lancar dan baik.

\section{DAFTAR PUSTAKA}

Adam dan Aulia P. 2018. Penanaman Mangrove untuk Konservasi Pantai Tanjung Sengkuang. Minda Baharu Vol. 2 : 29-37.

Amin, A.H., Mimien H.I., Fatchur R., Istamar S. 2016. Sosialisasi Pengelolaan Hutan Mangrove Berkelanjutan Sebagai Upaya Peningkatan Kesadaran Siswa Dan Masyarakat Akan Dampak Alih Fungsi Lahan Mangrove (Studi Kasus Di Kecamatan Bangkala Kabupaten Jeneponto Sulawesi Selatan). Prosiding Seminar Nasional Biologi 2016. Universitas Negeri Surabaya.

Badan Pusat Statistik Kabupaten Konawe, Kecamatan Soropia dalam Angka 2018. BPS Kabupaten Konawe.

Handaka, AA., I. Riyantini, M.Y. Awaluddin. 2007. Kepedulian Masyarakat terhadap Pencemaran di Wilayah Pesisir Pameungpeuk Kabupaten Garut. Jurnal Akuatika. FPIK Unpad. 
Hardianti S., Eka P., Paskal S. 2014. Hubungan Pengetahuan Konservasi dengan Persepsi Nelayan tentang Kegiatan Penanaman Mangrove di KampungGarapanDesaTanjung Pasir Tangerang. Jurnal: Biosfer Vol VI No.2: 10-14.

Kementerian Kelautan dan Perikanan RI. 2018. Refleksi 2017 dan Outlook 2018 Membangun dan Menjaga Ekosistem Laut Indonesia Bersama Ditjen Pengelolaan Ruang Laut. Direktorat Jenderal Pengelolaan Ruang Laut. Jakarta.

Nontji, A. Laut Nusantara. Jakarta: Penerbit Djambatan.

Pramudji, 2001. Ekosistem Hutan Mangrove dan Peranannya sebagai Habitat Berbagai Fauna Aquatik. Oseana, Vol. XXVI No. 4 : 13-23.

Priyono, A. 2010. Panduan Praktis Teknik Rehabilitasi Mangrove di Kawasan Pesisir Indonesia. Semarang: KeSEMaT.

Utami, A., dan Ahmad M. 2016. Peran Lembaga Swadaya Masyarakat dalam Pengelolaan Mangrove Pasca Tsunami di Desa Kajhu, Baitusalam, Aceh Besar, NAD. Skripsi. Yogyakarta: Program Studi Kehutanan Universitas Gadjah Mada. 